\title{
The Logical Problems of Hindi Speakers while Learning French as Foreign Language
}

Rajesh Kumar

Assistant Professor French

Amity School of Languages

Amity University Chhattisgarh

Chhattisgarh, India

amitchaturvedi3625@gmail.com

As we all know, every human being has LAD (Language Acquisition Device), which helps to learn, to understand and to speak a language. We all human being learn or understand at least one language by birth, which we call mother tongue or first language and it comes with feelings inside us automatic. If we think something in our mother tongue, then we can describe it very easily, without any hesitation. To speak or to understand mother tongue, there is no need to learn or study properly, it comes from inside. But while learning a second language or foreign language we face many challenges, like: mother tongue influence, social background, cultural background, pronunciation, medium language and teaching methods too.

In this article I want to focus on some problematic points of French Language. Learner coming from Hindi Speaking background, which they have faced during whole learning periods. Some points vary person to person, but some points are same and some points change with time. At every learning phase there are different problems. For beginners there are some other problems and another side for next level learners there are some other problems. These problems 
vary not only with learning phase but also vary with age groups, because teenagers learn more than their experience-literally, so they have different types of problems and other side adults learn not only in class room rather they learn with their experiences too, so they have some other types of problems.

Every language has its own grammatical rules to frame the sentences. Speaking part of French Language is a bit complicated; because it is totally different from other language. In this article we will read about some logical differences and barriers, which are affecting capacity of Indian learners.

\section{Cultural Differences:}

Learner's culture can be a barrier to foreign language learning. Cultural differences may cause confusion and cultural misunderstandings. It can be a barrier while communicating because of cultural differences.

Learning a second language means learning to speak and absorb it. But the learners would not be able to reach high level of proficiency unless they train their mind to think in the context of the target language. Then only the learners will be able to reach pragmatic and sociolinguistic competence.

Language is a part of culture. If anyone is learning second or third language, then one should also learn culture parallel, so that they can feel the language deeply and the exact meaning of words. Because every language has its own culture and French culture and Indian culture are quite different. So this cultural difference creates always problems while learning French language. When we learn both cultures, then we can compare both culture and gain these cultural words and meanings easily. 


\section{Semantic Barriers:}

Semantic refers to specific meaning of a word, especially in academic circles. Semantic is the science of meaning. The same words and symbols may have different meaning. Semantics are the misunderstandings that the people have different meaning and concepts because of the varied backgrounds. Semantic barriers arise due to difference in language, education and culture. Social values, difference in judgment, inferiority complex, biased attitude, time pressure, communication inability contributes the semantic barriers, which broaden the psychological difference between the learning processes. When we learn a foreign language, this barrier hurdles our learning methodology. This semantic barrier develops due to the different family backgrounds and living conditions. It is our living environment that affects our understanding, context and meaning of any language.

As a student I have always realized that I always used to translate French sentences and now I can say it was wrong method to learn a foreign language. Because while translating most of time we don't get the exact meaning of sentences like; I am going to "Acheter un café " you cannot tell from the phrase itself whether I need a ten minute break with a hot drink. In such cases learners should not go with translation rather they should go with exact mean and feel of sentences.

\section{Phonology Differences:}

The hardest challenge, that any new French learner faces is the typical French speaking. There are some differences in the sound systems of the languages that can cause French learner's problems of comprehension and speech production. A typical pronunciation problem is the inability to correctly articulate the vowel sounds in minimal pairs such as ship / sheep, live / 
leave, full / fool. Because the tip of the tongue is not used in speaking French, learners often have problems with words containing the letters th $(/ \theta / / \delta /)$, such as then, think and clothes.

\section{No Environment for Communication:}

Communication is like backbone of any language. If you are not speaking a language or dialect for long time or you are not practicing it daily or if you are not communicating in this language then it will always be difficult to learn or to gain. We learn or we speak our mother tongue very easily, because we communicate or we use or I can say, we have to communicate in our mother tongue. We have such type of mother tongue environment, that's why we face rarely problems with mother tongue. But another side with French language, we don't have such environment neither at home nor in society. We learn new words, new sentences and new rules, but we cannot apply it in our daily routine to communicate with friends and family. Thus we learn foreign language on paper like a subject not like a language. We learn formally not practically, that's why we often forget words in French. We memorize it but unable to apply on that particular occasion, because we get rarely French communicating or speaking environment. Indian students who learn French as second or third language, they have these communicating problems often, because they don't have such environment, neither in society nor at home and they don't have language lab facility too. One can also find Tandem partners or friends rarely here, and without communication no one can imagine the existence of a language. Communicating practices are more challenging for language learners here. 


\section{Biological Barriers}

Biological barriers also play a vital role in learning a language. The biological barriers consist of many factors.

- Cognitive functioning

- Physical impairments (Deaf, Blind etc.)

- Psychological fitness

- Age and health

- Let us discuss each one by one.

\subsection{Cognitive Learning Theory}

Cognitive learning theory (CLT) is about understanding working of human mind while learning. The theory is centered how the brain processes the information and how learning process goes on with this processed information. Cognitive learning method depends on the mental processes, by which the learners take in, interpret, store and retrieve information. These mental processes depend on many elements mainly: attention, observation, perception, interpretation, memory (storing \& retrieval), forming generalizations. It is believed that the learner acts on beliefs, thoughts, knowledge, attitudes, feelings as well as the environment when interpreting new language.

\subsection{Physical Impairments (deaf, blind etc.)}

Physical impairments lead to delay in learning a new language. It slows down the pace of learning a new language. We have to go through a process that includes reading, writing, listening, speaking. Any physical impairment either hampers or affects any of these processes. 
These various processes help in observing a new language, for example speech language impairment involves the problem in articulation of target language words. The physically impaired learners face different kinds of challenges. We can have a simple example; a deaf child faces challenges because of the limitation of linguistic input reaching the children. The main educational hurdle forced by deaf student's acquisition of the language of the community. The grammatical competence is not observed properly in the way it should be.

These physical impairments problem face not only Indian learners rather all learners in the world too. These impairments affects gaining capacity and representing capacity as well as.

\subsection{Psychological Fitness}

To be fit psychologically, it is also necessary to learn a foreign language. As Indian students and basically from Hindi background, we have always fear before learning a foreign language, that it would be very difficult and we cannot learn or speak. I can say we have anxiety of foreign language learning. We make our self mentally weak before we start learning. We start learning a language as subject not as communicative language and it creates burden in our mind and because of such anxiety we unable to memorize the words or I can say to apply the words or sentences at right time and place. A learner should be fit mentally or psychologically.

\subsection{Age and Health}

Age and physical health of learner effect his or her learning capacity. Teenage students learn faster or I can say gain or memorize faster, because their brain is like a blank paper, they can put in what they want, but it doesn't mean that they don't have any problems while learning French, of course they have also problems, but other types of like: comparative learning method, 
less social and cultural knowledge and less experience. These factors play a big role with teenage learners.

Other sides with adults or mature learners have more confusion, because they have already more perception and experience in their mind, that's why they always go with comparative learning method and it creates confusion in their mind.

\section{The Role of Comparative Approach:}

The general problem a foreign language learner forces while learning it is that they start learning and thinking the new language in their native language. This comparative approach instead of helping and paving our path easy creates hurdles in observing the language. It's not correct to consider a language as a number of words and sentences or as a row of grammar rules, that one has to know for a successful communication. This comparative approach would only work when we acquire qualities of the second language personality. So, besides learning a foreign language, we must think of the other factors. Let us discuss the influence of surrounding factors.

Every country has its own special features due to different historical, geographical, political and other factors. When comparing India and France, one can see enormous differences. France is the most populated country in Europe. It covers an area of $357021 \mathrm{sq} . \mathrm{km}$. and it has over 80 million inhabitants. In India about 133 crores people live in an area of 3,287,263 sq. km. As a result, Germany is known for its order, punctuality and striving to organize their lives according to rules. It's impossible to create such order on the enormous Indian Territory. All these special features are reflected in the languages of these two countries. When we look attentively, we can notice a fixed word order. In a declarative sentence a verb is usually at the 
second place. It's like an anchor around which other words are swimming. One can say, "Je vais chez moi . (I go to home .)", The verb takes always second position in French sentences.

Subordinate clauses have also a fixed word order. At the beginning we find a word that introduces a subordinate clause (for example, the word "qui - that"), first comes a subject and at the very end stands a predicate. Subordinate clauses are considered as a stuffing between "a subject" and "a predicate".

Conclusion: A Quick Fix:

Everybody makes mistakes when learning French. Mistakes are part of normal learning process. What matters, however, is whether you are able to recognize them and correct them. Find somebody who is a French native speaker, a friend or a colleague that is not difficult in this technology advanced age where we lots of social apps that instantly connect with people around the globe and tell them to tell you where you most commonly make mistakes. Often, if you manage to address half a dozen of the most frequent repetitive mistakes, you can do away up to $80 \%$ of all mistakes you make when speaking French. More important while learning French immerses yourself in the French language by creating a Mini-French in your home. 


\section{References}

Bloomfield, L “Language” 1935.

Allen, C. "Journal of Linguistics” 1986.

H. Douglas Brown "Principles of Language Learning and Teaching."

Weblinks:

"The Logical Problem of Second Language Acquisition".

https://conference.pixelonline.net/conferences/edu_future2012/common/download/Paper _pdf/160-SLA04-FP-Dralo-FOE2012.pdf

"Semantic and Syntactic Problems Faced by Students in 2nd Language Acquisition".

file://C:/Users/BSB08/Downloads/295748373-Semantic-and-Syntactic-Problems-Facedby-Students-in-2nd-Language-Acquisition.pdf

"Foreign Language Learning Difficulties and Teaching Strategies"

https://files.eric.ed.gov/fulltext/ED501062.pdf 